\title{
Photocatalytic degradation of organic dyes using composite nanofibers under UV irradiation
}

\author{
Ahmed Salama $^{1} \cdot$ Alaa Mohamed $^{1,2}$ (1) Nada M. Aboamera ${ }^{1} \cdot$ T. A. Osman ${ }^{3} \cdot$ A. Khattab $^{3}$
}

Received: 21 September 2017 / Accepted: 10 January 2018 / Published online: 3 February 2018

(c) Springer-Verlag GmbH Germany, part of Springer Nature 2018

\begin{abstract}
In this work, photocatalytic degradation of organic dyes such as methylene blue (MB) and indigo carmine (IC) have been studied by composite nanofibers systems containing cellulose acetate (CA), multiwall carbon nanotubes (CNT) and $\mathrm{TiO}_{2}$ nanoparticles under UV light. The amino factionalized $\mathrm{TiO}_{2}-\mathrm{NH}_{2} \mathrm{NPs}$ cross-linked to the CA/CNT composite nanofibers works as a semiconductor catalyst. The morphology and crystallinity were characterized by scanning electron microscopy, transmission electron microscopy (TEM), X-ray diffraction, and Fourier transform infrared spectroscopy. It was also seen that many factors affected the photodegradation rate, mainly the $\mathrm{pH}$ of the solution and the dye concentration, temperature, etc. The study demonstrated that IC degrades at a higher rate than MB. The maximum photodegradation rate of both organic dyes was achieved at a $\mathrm{pH}$ 2. In comparison to other studies, this work achieved high photodegradation rate in lower time and using less power intensity.
\end{abstract}

Keywords Photocatalytic $\cdot$ Electrospinning $\cdot$ Composite nanofibers $\cdot$ UV light

\section{Introduction}

Water pollution is a considerable threat to human health. Water is the most vital resource for people and for ecosystems. However, industrialization and urbanization led the water quality to deteriorate, thus negatively impacting humans and all other living organisms. The low quality of the water is also a major problem in agriculture and food production. Other sectors, such as the economy, are greatly impacted as well. The most common water pollutants are organic dyes and pigments, which are present in many industrial effluents such as textile, lather, paper, cosmetics, and printing (Zheng et al. 2008). Many techniques can be employed to eliminate those pollutants from the wastewater. Those techniques mainly involve chemical, physical or biological processes (Mohamed et al. 2016). Contaminants

Alaa Mohamed

alakha@kth.se

1 Production Engineering and Printing Technology Department, Akhbar El Yom Academy, Giza 12655, Egypt

2 Egypt Nanotechnology Center, EGNC, Cairo University, Giza 12613, Egypt

3 Mechanical Design and Production Engineering Department, Cairo University, Giza 12613, Egypt degradation using photocatalytic processes with the aid of composite nanofibers had been emerged in the 1970s and are still developing. The photocatalytic processes mainly use semiconductors catalysts such as $\left(\mathrm{TiO}_{2}, \mathrm{Fe}_{2} \mathrm{O}_{3}, \mathrm{ZnO}\right)$ under light exposure (UV light or sun light) to degrade the organic and inorganic contaminants (Kuriakose et al. 2015; Mohamed et al. 2017). Most of the researchers is now focusing on the photocatalytic techniques using composite nanofibers for the treatment of the wastewater and degrading of the dyes due to its high efficiency and low-cost technique (Mohamed et al. 2016; Xu et al. 2010).

Many semiconductor catalysts can be used, but titania $\left(\mathrm{TiO}_{2}\right)$ is the most commonly used semiconductor catalyst due to its cheap cost combined with a high photocatalytic activity. Moreover, titania is readily available, non-toxic and can induce complete mineralization by degrading organic pollutants (Eskandarloo and Badiei 2014). It can be found in three crystalline phases: brookite, rutile and anatase. However, many previous studies have favored the use of the anatase form of titania in the photocatalytic process to degrade different types of dyes. Nasirian et al. (2017) have showed that the degradation efficiency of MO and CR removal using $\mathrm{Fe}_{2} \mathrm{O}_{3} / \mathrm{TiO}_{2}$ composite nanofibers is 61.5 and $46.8 \%$, respectively. Dhanya and Aparna (2016) have illustrated the importance of adding $\mathrm{TiO} 2$ to 
the chitosan for MO photocatalytic degradation and have obtained a $100 \%$ degradation efficiency. Muneer et al. (2005) have shown the effects of the structure and size of the UV100, PC500, TTP and Degussa P25 photocatalysts. They have found that Degussa P25 has the highest efficiency in the degradation of the dyes. In this regard, this research is based on the usage of Degussa P25 $\mathrm{TiO}_{2}$ NPs as a semiconductor photocatalyst in the degradation processes of MB and IC.

The surface of the nanofibers has to be activated by reactive group such as amines, carboxyls, and hydroxyls to be able to exploit the advantage of the nanofiber mesh. Primary amines were considered the most effective group to promote cell adhesion, due to their high reactivity and high stability in water. Manakhov et al. (2015) have reported the results of adding the primary amine group onto nanofibers of polycaprolactone in the coating process, using CPA plasma polymerization. This study describes the amino factionalized $\mathrm{TiO}_{2} \mathrm{NP}_{\mathrm{S}}$ cross-linking on the CA-CNT composite nanofibers surface. By analyzing the photocatalytic degradation of IC and MB, many observations can be generated to conclude on how different parameters affect the photodegradation rate. Hence, the goal of this study is to investigate the factors that affect the photocatalytic efficiencies of $\mathrm{MB}$ and IC using the synthesis $\mathrm{CA}-\mathrm{CNT} / \mathrm{TiO}_{2}-\mathrm{NH}_{2}$ composite nanofibers.

\section{Experimental}

\section{Material}

Cellulose acetate/carbon nanotube composite nanofibers were prepared using electrospinning technique as discussed in the previous work (Mohamed et al. 2017). Titanium dioxide NPs $\left(\mathrm{TiO}_{2}\right.$ Degussa P-25), 3-aminopropyltriethoxysilane (APTES), glutaraldehyde (GA), indigo carmine (IC) and methylene blue (MB) dyes, hydrochloric acid (HCI) and sodium hydroxide $(\mathrm{NaOH})$ were purchased from Sigma Aldrich.

\section{Characterization}

The morphology, and crystalline were characterized by scanning electron microscopy (SEM) (Quanta FEG 250, Republic Czech), transmission electron microscopy (TEM) (JEM-2100 JEOL Japan), X-ray diffraction (XRD) (D/MAX2500 diffractometer, Rigaku, Japan), and Fourier transform infrared spectroscopy (FTIR) (Jasco, FT-IR 6100, Japan). The diameters of the fibers were measured by image processing software (Image J, 1.48v).

\section{Samples preparation}

Cellulose acetate/carbon nanotube composite nanofibers fabricated using electrospinning technique were crosslinked to $\mathrm{TiO}_{2}-\mathrm{NH}_{2} \mathrm{NPs}$. The composite nanofibers was submerged in the cross-linking medium which, consisting of $100 \mathrm{~mL}$ distilled water and $2.5 \mathrm{wt} \%$ glutaraldehyde (GA) and mechanically shaken for $24 \mathrm{~h}$ at room temperature. After this process, the composite nanofibers were washed by the distilled water. The surface functionalization $\mathrm{TiO}_{2}-\mathrm{NH}_{2} \mathrm{NPs}$ were added to $5 \mathrm{~mL}$ distilled water, and sonicated for $2 \mathrm{~h}$, then added to the composite nanofibers and shaken for $24 \mathrm{~h}$. The $\mathrm{CA}-\mathrm{CNT} / \mathrm{TiO}_{2}-\mathrm{NH}_{2}$ composite nanofibers was finally washed with distilled water and dried in air at room temperature (Mohamed et al. 2015).

\section{Photodegradation experiments}

Using a UV lamp (315-400 nm) of 40 watts for the UV light irradiation, the photocatalytic activity of CA-CNT/ $\mathrm{TiO}_{2}-\mathrm{NH}_{2}$ composite nanofibers was studied by recording the photodegradation of IC and MB. Different MB and IC concentrations were used $(10,30,50 \mathrm{mg} / \mathrm{L})$ and at different pHs starting from 2 to 8 . The composite nanofibers (diameter of $12 \mathrm{~cm})$ were placed in a column $(2 \mathrm{~cm} \times 13 \mathrm{~cm})$. A $50 \mathrm{~mL}$ solution of IC or MB was added to the composite nanofibers and kept shaking for $30 \mathrm{~min}$ in the dark. After that, $3 \mathrm{~mL}$ volume of the dye solution was taken at uniform intervals of time, while shaking under the UV light irradiation. Using the UV-Vis/NIR spectrophotometer, the dye concentration was obtained. After each experiment, the composite nanofibers were washed many times using distilled water to be able to be reused again (Seo et al. 2017; Mohamed et al. 2017; Nguyen and Juang 2015). The photodegradation efficiency was calculated accordingly:

Photodegradation efficiency $(\%)=\frac{C_{\mathrm{i}}-C_{t}}{C_{\mathrm{i}}} \times 100$,

where $C_{\mathrm{i}}$ is the initial concentration and $C_{t}$ is the concentration at time $(t)$.

\section{Results and discussion}

\section{Characterization of CA-CNT/TiO $2-\mathrm{NH}_{2}$ composite nanofibers}

The SEM images of CA-CNT/ $\mathrm{TiO}_{2}-\mathrm{NH}_{2}$ are shown in Fig. 1. The figure shows continuous and smooth morphology and free of aggregates nanofibers having an average diameter about $430 \pm 20 \mathrm{~nm}$. The figure also shows the distribution 

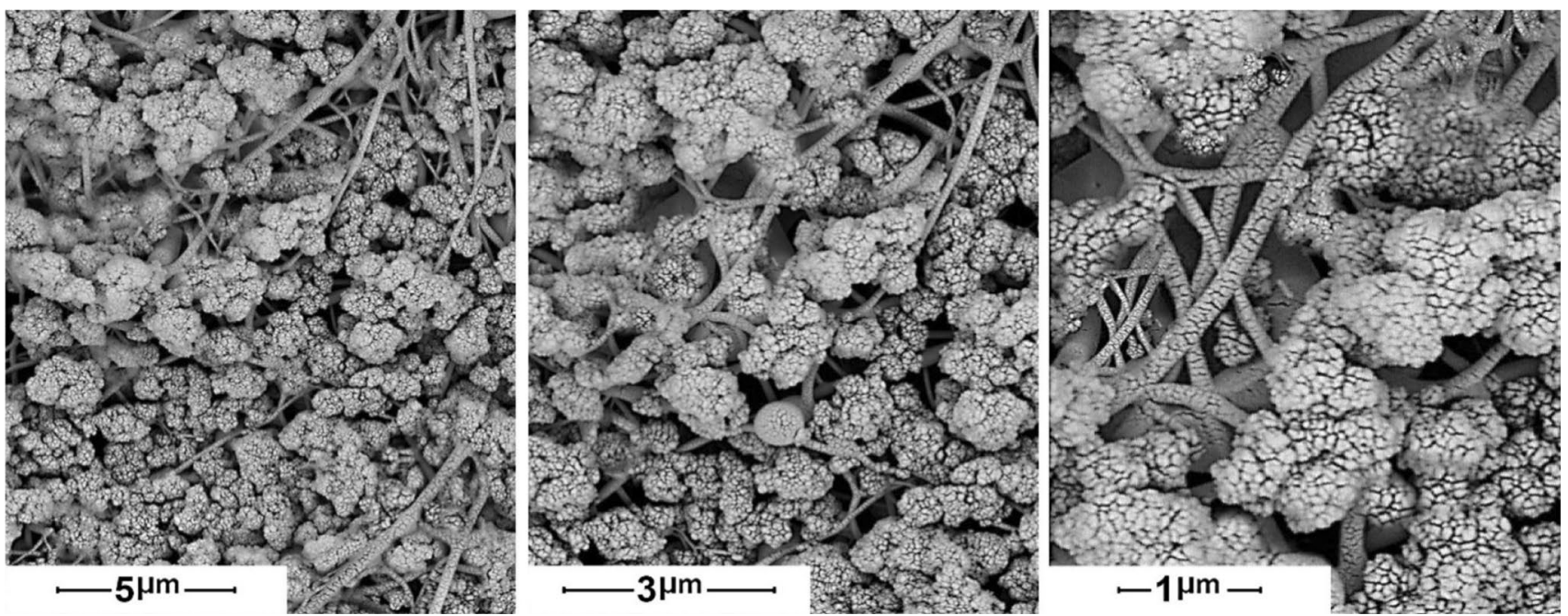

Fig. 1 SEM images of $\mathrm{CA}-\mathrm{CNT} / \mathrm{TiO}_{2}-\mathrm{NH}_{2}$ composite nanofibers

of the amino factionalized $\mathrm{TiO}_{2}$ NPs on the surface of the CA-CNT composite nanofibers which occurred by the cross-linking process. In addition, Fig. 2 shows the TEM images of $\mathrm{CA}-\mathrm{CNT} / \mathrm{TiO}_{2}-\mathrm{NH}_{2}$, which, approved the presence of $\mathrm{TiO}_{2}-\mathrm{NH}_{2}$ and show the adhesion of $\mathrm{TiO}_{2}-\mathrm{NH}_{2}$ to the surface of the CA-CNT composite nanofibers.

The FT-IR spectral of CA-CNT and CA-CNT/TiO ${ }_{2}-\mathrm{NH}_{2}$ confirms the surface functionalization of the fabricated composite nanofibers. The IR spectral of CA-CNT shows the following peaks: $(\mathrm{OH})$ peak at $3500 \mathrm{~cm}^{-1},(\mathrm{C}=\mathrm{O})$ peak at $1745 \mathrm{~cm}^{-1}$ and $(\mathrm{N}-\mathrm{O})$ peak at $900 \mathrm{~cm}^{-1}$ which are shown in Fig. 3a. After adding $\mathrm{TiO}_{2}-\mathrm{NH}_{2}$, the carbonyl and amino particles break down. The oxygen and nitrogen molecules are separated, which causes the formation of amidoxime (AO) after the molecules rearrangement. Figure $3 \mathrm{~b}$ shows the IR spectral of CA-CNT/TiO ${ }_{2}-\mathrm{NH}_{2}$. The figure confirms the presence of $\mathrm{NH}_{2}$ and illustrates the conversion of nitrile to amidoxime. More specifically, the conversion is confirmed by absorption in the range of $3300-3500 \mathrm{~cm}^{-1}$ which corresponds to $\mathrm{N}-\mathrm{H}$ and $\mathrm{O}-\mathrm{H}$ vibrations, and the bending vibrations of the amine group $\mathrm{NH}$ or $\mathrm{NH}_{2}$ at $1600 \mathrm{~cm}^{-1}$.

In addition, X-ray diffraction (XRD) analysis was performed to analyze the effect of $\mathrm{CNT}$ and $\mathrm{TiO}_{2}$ on the crystalline structure of the $\mathrm{CA}$. The reflection peaks of CA were found at $12^{\circ}$ and $20^{\circ}$ as shown in Fig. 4. Moreover, the graph shows the presence of CNT which causes a strong peak
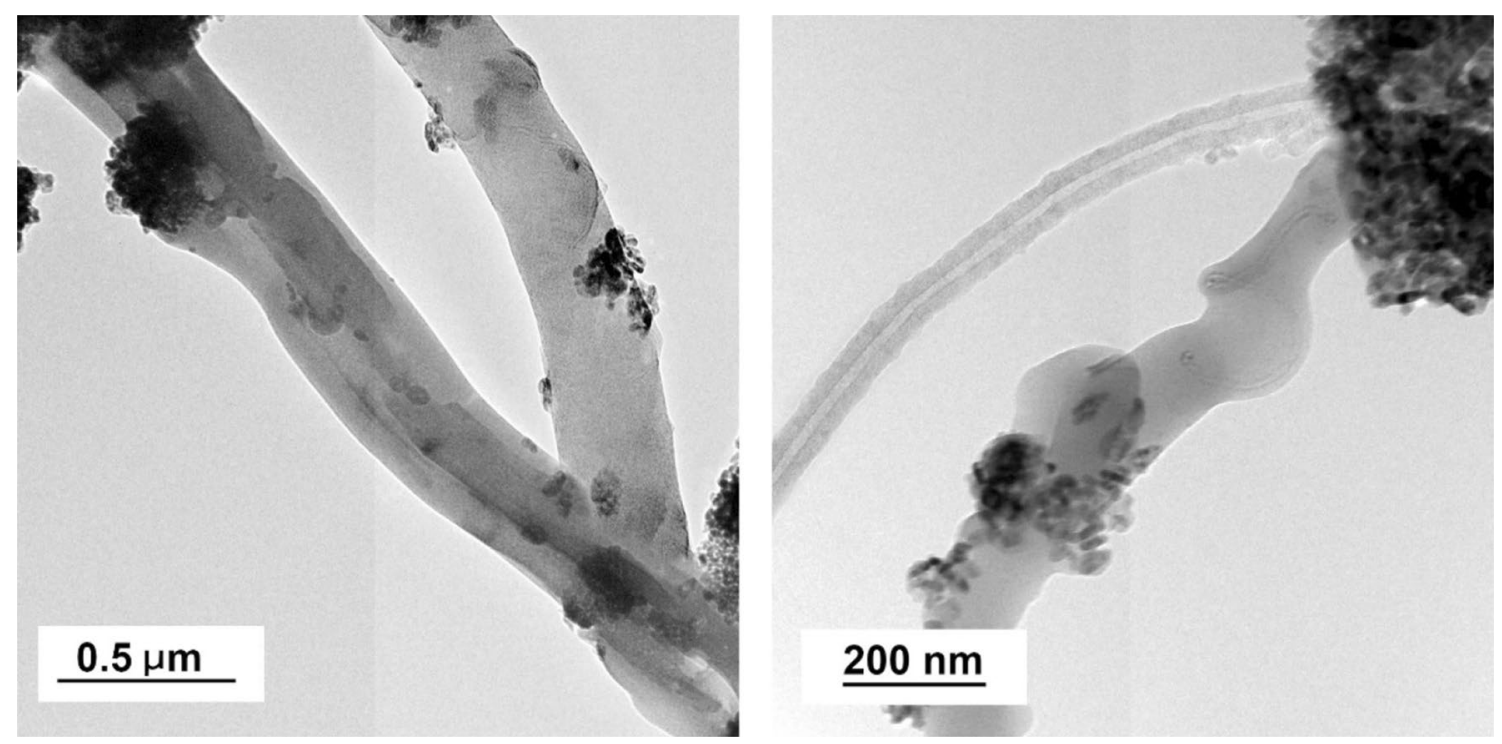

Fig. 2 TEM images of $\mathrm{CA}-\mathrm{CNT} / \mathrm{TiO}_{2}-\mathrm{NH}_{2}$ composite nanofibers

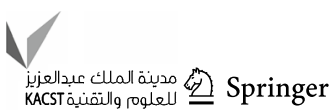


Fig. 3 FT-IR spectra of a CA$\mathrm{CNT}$ and $\mathbf{b} \mathrm{CA}-\mathrm{CNT} / \mathrm{TiO}_{2}-$ $\mathrm{NH}_{2}$ composite nanofibers
Fig. 4 XRD of $\mathrm{CA}-\mathrm{CNT} / \mathrm{TiO}_{2}-$ $\mathrm{NH}_{2}$ composite nanofibers
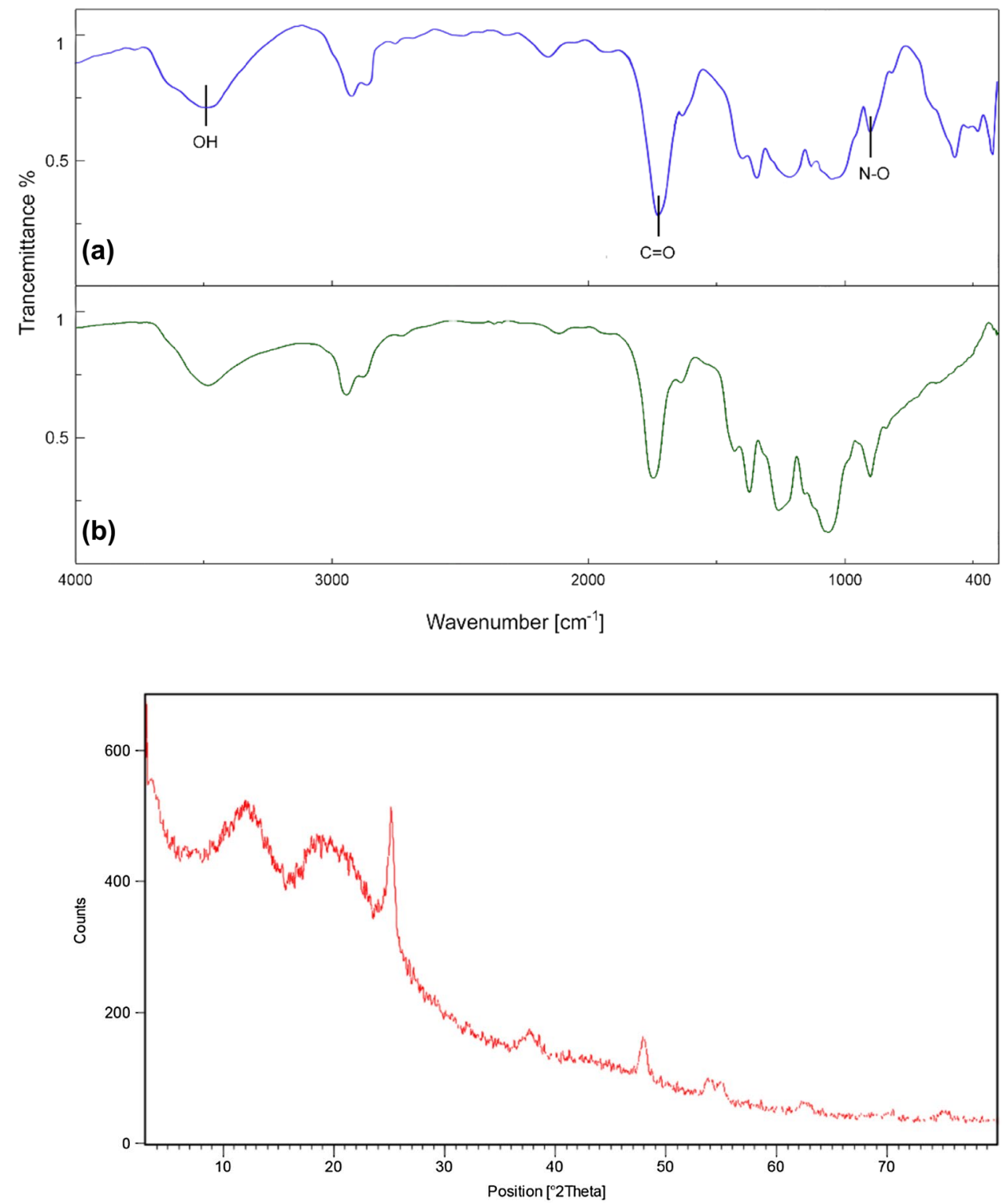

at $25.6^{\circ}$. In addition, the peaks at $25.19^{\circ}, 37.69^{\circ}, 47.98^{\circ}$, $53.85^{\circ}, 62.53^{\circ}$, and $75.12^{\circ}$ confirm the presence of $\mathrm{TiO}_{2}$.

\section{Photodegradation performance}

\section{The effect of dye concentration}

The photocatalytic degradation rate of a certain dye or pollutant depends on its concentration, nature and on the presence of other existing compounds in the water matrix. Figure 5 shows the effect of the dye's concentration on the photodegradation efficiency for $\mathrm{MB}$ and IC. The degradation efficiencies were studied at 10, 30, and $50 \mathrm{ppm}$. The result indicated that the degradation efficiencies were, respectively, 100, 80, and 70\% for MB and 100, 90 and $80 \%$ for IC. High concentration of the dye activated the photocatalytic process,

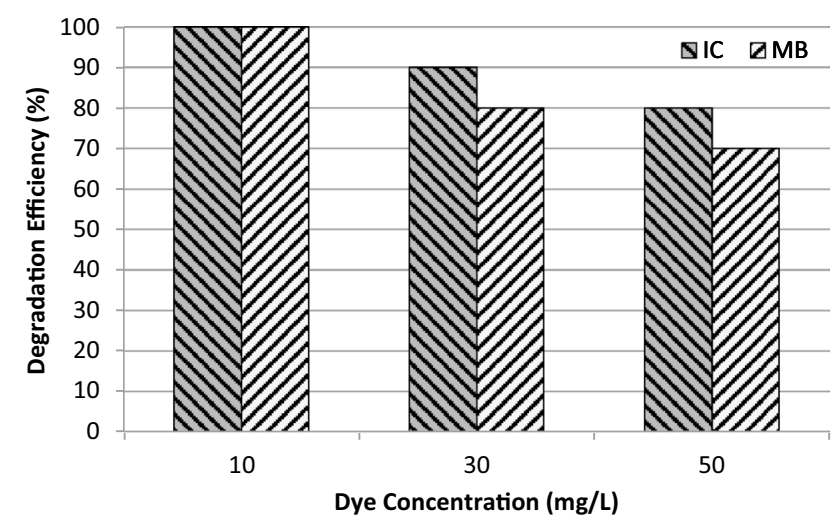

Fig. 5 The effect of the dyes concentration on the photodegradation efficiency 


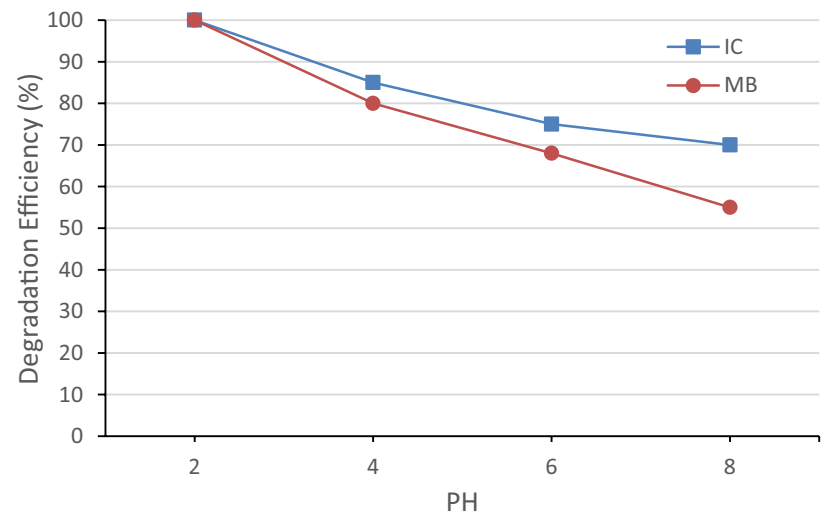

Fig. 6 The effect of the $\mathrm{pH}$ on the photodegradation efficiency for IC and $\mathrm{MB}$ at $10 \mathrm{ppm}$

but reduced the degradation rate. This result is due to the saturated surface of the $\mathrm{TiO}_{2}$ which is caused by the high concentration of the dye. In this regard, the photocatalytic degradation reaction will be deactivated. Furthermore, the nature of the dyes is such that they adhere effectively to the surface of the photocatalyst, making the process of removing the dyes from the solution would be more effective.

\section{The effect of the $\mathrm{pH}$ of the solution}

The photocatalytic degradation of dye is mainly dependent on the $\mathrm{pH}$ value due to its effect on the catalyst charge, aggregates' size, and valance and conductance bonds position. The $\mathrm{TiO}_{2}$ maximum oxidizing capacity was found at lower $\mathrm{pH}$ value. In this regard, the degradation of IC and MB was studied at different $\mathrm{pH}$ values in range of (2-8) to find the value that gives the maximum degradation efficiency. The influence of $\mathrm{pH}$ on degradation efficiency for both IC and MB can be seen in Fig. 6. The figure shows that the acidic conditions help to reach higher degradation efficiencies for IC and MB. The maximum degradation efficiency occurred at $\mathrm{pH} 2$. This results may be due to the electrostatic interactions between the positive catalyst surface and the
Fig. 7 The effect of reaction temperature on the photodegradation rate
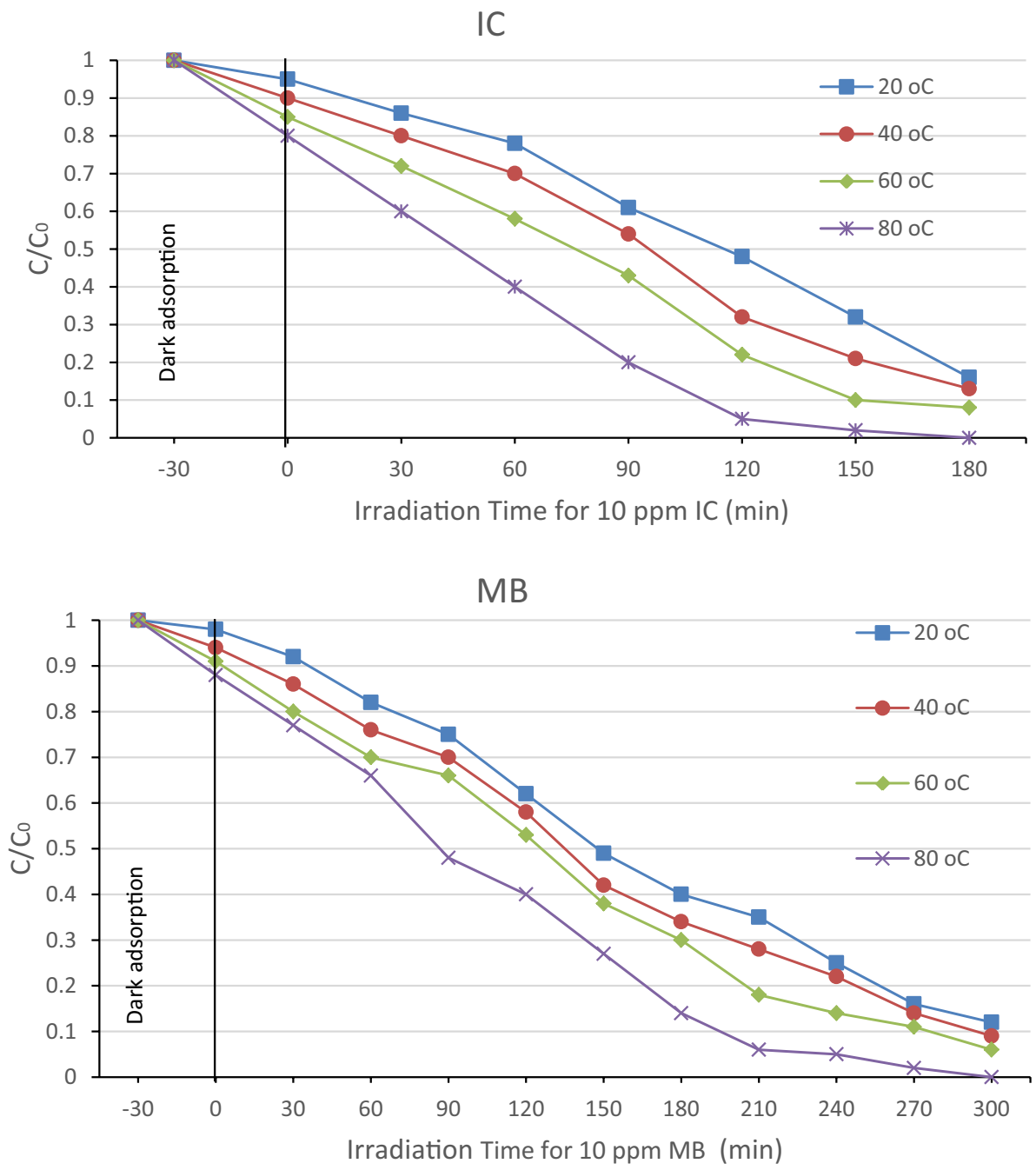
Table 1 Comparison of photocatalytic activities of materials used for photocatalytic degradation of dyes under UV light

\begin{tabular}{lllllll}
\hline Material & Model type & $\begin{array}{l}\text { Model concen- } \\
\text { tration (PPM) }\end{array}$ & Degradation (\%) & $\begin{array}{l}\text { Lamp } \\
\text { power (W) }\end{array}$ & $\begin{array}{l}\text { Max. time for max. } \\
\text { degradation (min) }\end{array}$ & References \\
\hline $\mathrm{Cu}_{2} \mathrm{O} / \mathrm{Bi}_{2} \mathrm{WO}_{6}$ & Butyric acid & 200 & 92 & 500 & 400 & Zheng et al. (2017) \\
$\mathrm{TiO}_{2} /$ chitosan & $\mathrm{MO}$ & & 100 & & 360 & $\begin{array}{l}\text { Dhanya and Aparna (2016) } \\
\text { Boukhatem et al. (2017) }\end{array}$ \\
$\mathrm{Cu}_{0.6} \mathrm{Cd}_{0.4} \mathrm{~S}$ & Phenol & 20 & 86 & & 250 & Atchudan et al. (2017) \\
$\mathrm{TiO}_{2}-\mathrm{GO}$ & $\mathrm{MO}$ & & 84 & 240 & Nasirian et al. (2017) \\
$\mathrm{Fe}_{2} \mathrm{O}_{3} / \mathrm{TiO}_{2}$ & $\mathrm{MO}$ & 30 & 61.5 & 45 & 210 & Nasirian et al. (2017) \\
$\mathrm{Fe}_{2} \mathrm{O}_{3} / \mathrm{TiO}_{2}$ & $\mathrm{CR}$ & 30 & 46.8 & 45 & 210 & This work \\
$\mathrm{CA}-\mathrm{CNT} / \mathrm{TiO}_{2}-\mathrm{NH}_{2}$ & $\mathrm{IC}$ & 10 & 100 & 40 & 180 & This work \\
$\mathrm{CA}-\mathrm{CNT} / \mathrm{TiO}_{2}-\mathrm{NH}_{2}$ & $\mathrm{IC}$ & 30 & 90 & 40 & 180 & This work \\
$\mathrm{CA}-\mathrm{CNT} / \mathrm{TiO}_{2}-\mathrm{NH}_{2}$ & $\mathrm{IC}$ & 50 & 80 & 40 & 180 & This work \\
$\mathrm{CA}-\mathrm{CNT} / \mathrm{TiO}_{2}-\mathrm{NH}_{2}$ & $\mathrm{MB}$ & 10 & 100 & 40 & 300 & This work \\
$\mathrm{CA}-\mathrm{CNT} / \mathrm{TiO}_{2}-\mathrm{NH}_{2}$ & $\mathrm{MB}$ & 30 & 80 & 40 & 300 & This work \\
$\mathrm{CA}-\mathrm{CNT} / \mathrm{TiO}_{2}-\mathrm{NH}_{2}$ & $\mathrm{MB}$ & 50 & 70 & 40 & 300 & \\
\hline
\end{tabular}

dye anions which leading to strong adsorption of the dye anions on the metal oxide support. Moreover, the efficiency of the process increases by the formation of hydroxyl radicals, which formed when the hydroxide ions interact with the positive holes which are considered as the main oxidation species at low $\mathrm{pH}$.

\section{The effect of the reaction temperature}

The photodegradation process is very sensible to changes in temperature. This correlates with the results of this study, which shows that high temperature positively affects the degradation rate. In this regard, most researchers use solar energy, since it doesn't only include UV light which activates the photocatalytic process, but also infrared light which increases the temperature of the photocatalytic process (Barjasteh-Moghaddam and Habibi-Yangjeh 2011; Hu et al. 2010; Barakat et al. 2013). Figure 7 illustrates the effect of the temperature with the UV light in range from 20 to $80^{\circ} \mathrm{C}$. The figure shows that the highest temperature corresponds to the optimal degradation rate. This is due to the fact that more thermal energy is available for molecules at higher temperatures, as well as sufficient energy to react.

\section{The effect of the light intensity}

The photodegradation rate is affected by the light intensity. Table 1 proves that the photodegradation rate increased with the increase in the light intensity and vice versa.

\section{The effect of irradiation time}

Figure 8 illustrates the influence of the irradiation time on the photodegradation rate. It has been found that during the first 90 min of effective irradiation, the degradation rate was high, reaching $80 \%$ for IC and $52 \%$ for $\mathrm{MB}$. Then, the degradation
Fig. 8 The effect of irradiation time on the photodegradation rate

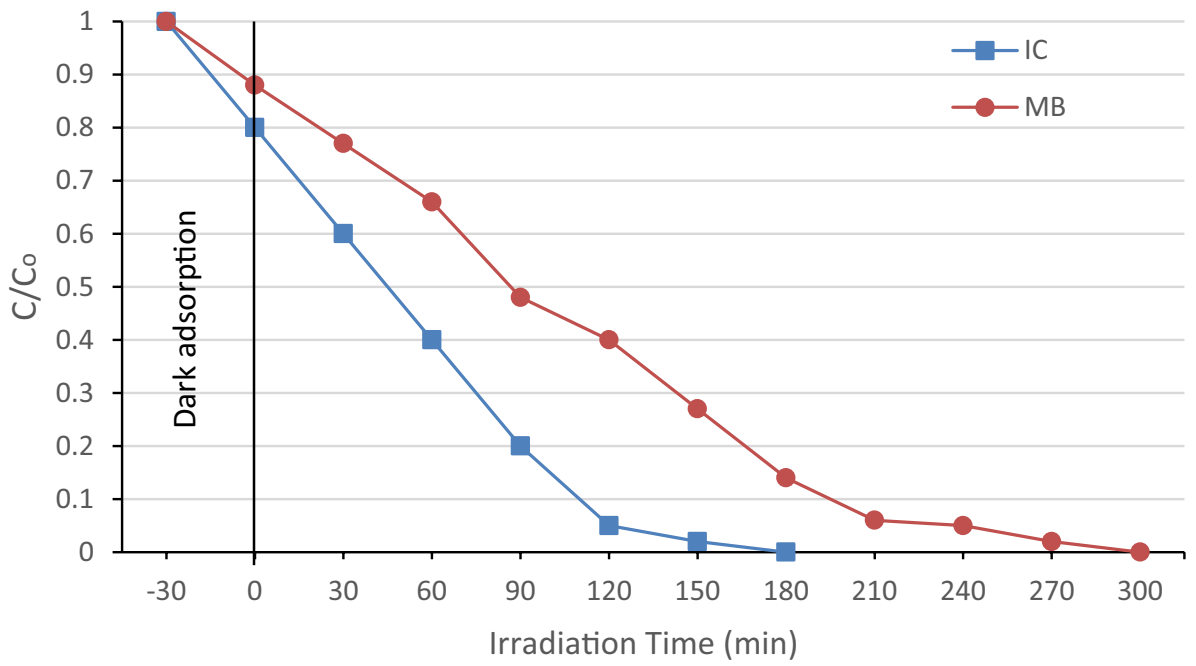


rate gradually decreased, reaching $95 \%$ after $120 \mathrm{~min}$ for IC and $210 \mathrm{~min}$ for MB. The full degradation occurred at $180 \mathrm{~min}$ for IC and $300 \mathrm{~min}$ for MB. The large degradation rate at the start of the process is caused by the high amount of the amino factionalized $\mathrm{TiO}_{2} \mathrm{NPs}$ on the surface of the CA-CNT composite nanofibers. The degradation rate is then reduced because of catalyst consumption.

\section{Conclusion}

The amino factionalized $\mathrm{TiO}_{2}-\mathrm{NH}_{2} \mathrm{NPs}$ cross-linked to the CA/CNT composite nanofibers was successfully prepared. The results shows smooth morphology and free of aggregation nanofiber with an average diameter about $430 \pm 20 \mathrm{~nm}$. The results also illustrated the good adhesion of the $\mathrm{TiO}_{2}-\mathrm{NH}_{2}$ to the surface of the CA-CNT composite nanofibers. The above study demonstrated that the fabricated composite nanofibers CA-CNT/ $/ \mathrm{TiO}_{2}-\mathrm{NH}_{2}$ is an effective photocatalyst in the degradation of water soluble dyes IC and MB. The full degradation was achieved at the lowest dye concentration $(10 \mathrm{ppm})$, the lowest $\mathrm{pH}$ value (2), at a high temperature $\left(80^{\circ} \mathrm{C}\right)$, and a low power intensity of the UV lamp $(40 \mathrm{~W})$. The full degradation of IC and MB needs 180 and $300 \mathrm{~min}$, respectively, to be achieved.

\section{References}

Atchudan R, Jebakumar TN, Edison TNJI, Perumal S, Karthikeyan D, Lee YR (2017) Effective photocatalytic degradation of anthropogenic dyes using graphene oxide grafting titanium dioxide nanoparticles under UV-light irradiation. J Photochem Photobiol A Chem 333:92-104

Barakat NAM, Kanjwal MA, Chronakis IS, Kim HY (2013) Influence of temperature on the photodegradation process using Ag-doped $\mathrm{TiO}_{2}$ nanostructures: negative impact with the nanofibers. J Mol Catal A Chem 366:333-340

Barjasteh-Moghaddam M, Habibi-Yangjeh A (2011) Effect of operational parameters on photodegradation of methylene blue on $\mathrm{ZnS}$ nanoparticles prepared in presence of an ionic liquid as a highly efficient photocatalyst. J Iran Chem Soc 8(1):S169-S175

Boukhatem H et al (2017) Photocatalytic activity of mont-La (6\%)-Cu0.6Cd0.4S catalyst for phenol degradation under near UV visible light irradiation. Appl Catal B Environ 211:114-125

Dhanya A, Aparna K (2016) Synthesis and evaluation of $\mathrm{TiO}_{2} /$ chitosan based hydrogel for the adsorptional photocatalytic degradation of azo and anthraquinone dye under UV light irradiation. Proc Technol 24:611-618

Eskandarloo H, Badiei A (2014) Photocatalytic application of titania nanoparticles for degradation of organic pollutants. In: Aliofkhazraei M (ed) Nanotechnology for Optics and Sensors, chap. 4, One Central Press, United Kingdom

Hu Q, Liu B, Song M, Zhao X (2010) Temperature effect on the photocatalytic degradation of methyl orange under UV-Vis light irradiation. J Wuhan Univ Technol Sci Ed 25(2):210-213
Kuriakose S, Satpati B, Mohapatra S (2015) Highly efficient photocatalytic degradation of organic dyes by $\mathrm{Cu}$ doped $\mathrm{ZnO}$ nanostructures. Phys Chem Chem Phys 17(38):25172-25181

Manakhov A, Nečas D, Čechal J, Pavliňák D, Eliáš M, Zajíčková L (2015) Deposition of stable amine coating onto polycaprolactone nanofibers by low pressure cyclopropylamine plasma polymerization. Thin Solid Films 581:7-13

Mohamed A, Osman TA, Khattab A, Zaki M (2015) Tribological behavior of carbon nanotubes as an additive on lithium grease. J Tribol 137:1

Mohamed A, El-Sayed R, Osman TA, Toprak MS, Muhammed M, Uheida A (2016a) Composite nanofibers for highly efficient photocatalytic degradation of organic dyes from contaminated water. Environ Res 145:18-25

Mohamed A, Osman TA, Toprak MS, Muhammed M, Yilmaz E, Uheida A (2016b) Visible light photocatalytic reduction of $\mathrm{Cr}(\mathrm{VI})$ by surface modified CNT/titanium dioxide composites nanofibers. J Mol Catal A Chem 424:45-53

Mohamed A, Osman TA, Toprak MS, Muhammed M, Uheida A (2017a) Surface functionalized composite nanofibers for efficient removal of arsenic from aqueous solutions. Chemosphere 180:108-116

Mohamed A et al (2017b) Photocatalytic degradation of organic dyes and enhanced mechanical properties of PAN/CNTs composite nanofibers. Sep Purif Technol 182:219-223

Mohamed A, Nasser WS, Osman TA, Toprak MS, Muhammed M, Uheida A (2017c) Removal of chromium(VI) from aqueous solutions using surface modified composite nanofibers. J Colloid Interface Sci 505:682-691

Muneer M, Qamar M, Saquib M, Bahnemann DW (2005) Heterogeneous photocatalysed reaction of three selected pesticide derivatives, propham, propachlor and tebuthiuron in aqueous suspensions of titanium dioxide. Chemosphere 61(4):457-468

Nasirian M, Bustillo-Lecompte CF, Mehrvar M (2017) Photocatalytic efficiency of $\mathrm{Fe}_{2} \mathrm{O}_{3} / \mathrm{TiO}_{2}$ for the degradation of typical dyes in textile industries: effects of calcination temperature and UV-assisted thermal synthesis. J Environ Manag 196:487-498

Nguyen AT, Juang R-S (2015) Photocatalytic degradation of $p$-chlorophenol by hybrid $\mathrm{H}_{2} \mathrm{O}_{2}$ and $\mathrm{TiO}_{2}$ in aqueous suspensions under UV irradiation. J Environ Manag 147:271-277

Seo HO et al (2017) Influence of humidity on the photo-catalytic degradation of acetaldehyde over $\mathrm{TiO}_{2}$ surface under UV light irradiation. Catal Today 295:102-109

$\mathrm{Xu} \mathrm{R}$ et al (2010) Photocatalytic degradation of organic dyes under solar light irradiation combined with $\mathrm{Er}^{3+}: \mathrm{YAlO}_{3} / \mathrm{Fe}-$ and $\mathrm{Co}-$ doped $\mathrm{TiO}_{2}$ coated composites. Sol Energy Mater Sol Cells 94(6): 1157-1165

Zheng B et al (2008) Water source protection and industrial development in the Shandong Peninsula, China from 1995 to 2004: a case study. Resour Conserv Recycl 52(8):1065-1076

Zheng X-J et al (2017) Photocatalytic degradation of butyric acid over $\mathrm{Cu}_{2} \mathrm{O} / \mathrm{Bi}_{2} \mathrm{WO}_{6}$ composites for simultaneous production of alkanes and hydrogen gas under UV irradiation. Int $\mathrm{J}$ Hydrogen Energy 42(12):7917-7929

Publisher's Note Springer Nature remains neutral with regard to jurisdictional claims in published maps and institutional affiliations. 